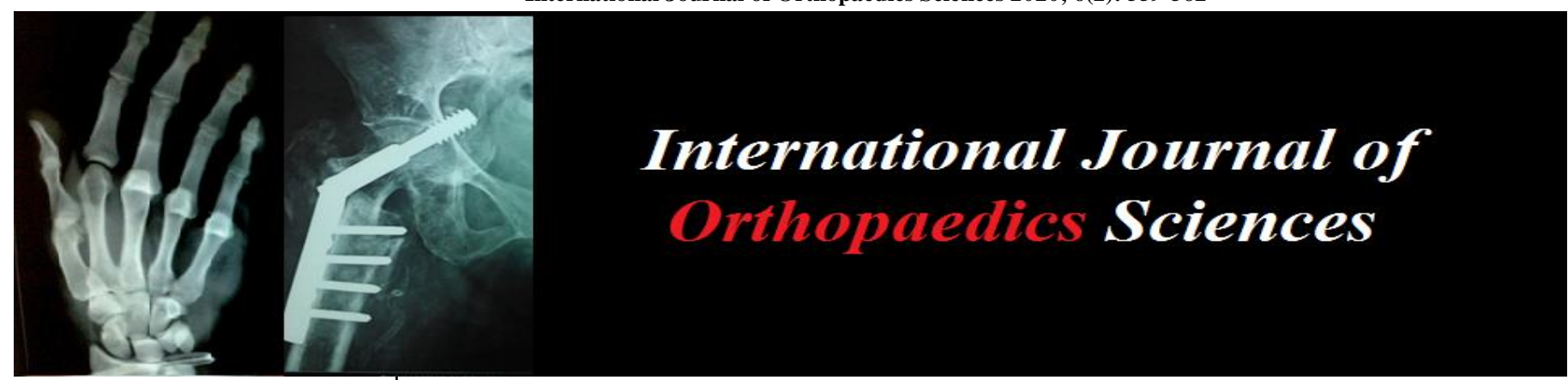

E-ISSN: 2395-1958

P-ISSN: 2706-6630

IJOS 2020; 6(2): 559-562

(C) 2020 IJOS

www.orthopaper.com

Received: 22-02-2020

Accepted: 24-03-2020

Dr. Edgar Nieto

Professor, Department of

Orthopedic and Traumatology

Los Andes University,

Orthopedic Specialist Doctor

Hospital Universitario de Los

Andes Merida, Venezuela
Corresponding Author: Dr. Edgar Nieto Professor, Department of Orthopedic and Traumatology Los Andes University, Orthopedic Specialist Doctor Hospital Universitario de Los Andes Merida, Venezuela

\section{Tibial pylon fracture associated with talus fracture and infrasindesmal spiral fibula. Case report and literature review}

\section{Dr. Edgar Nieto}

DOI: $\underline{\text { https://doi.org/10.22271/ortho.2020.v6.i2i.2098 }}$

\begin{abstract}
Combined fractures of the tibial pilon and the adjacent bones are infrequent. We present a case of a 59year-old female with a complex foot and ankle trauma resulting in an unusual combined ipsilateral fracture of the tibial pilon, talus neck, fibula spiral and dislocation. The fractures were treated by open reduction with anatomic reconstruction. To the best of our knowledge, this combination of fractures has not yet been reported in the literature.
\end{abstract}

Keywords: Ankle fracture. Low energy mechanism. Tibial pilon fracture. Distal fibula fracture. Neck talus fracture. Combined fractures. Ankle dislocation

\section{Introduction}

The tibial pylon is a fundamental part of the ankle, but when it fractures together with an articular cartilage surface lesion, it becomes a serious problem for the surgical team, due to the sequelae that it can cause. Its frequency only ranges between 7 and $10 \%$ of tibial fractures and less than $1 \%$ of those of the lower limb ${ }^{[1]}$. A significant percentage of them occur through a high energy mechanism ${ }^{[2]}$ causing soft tissue injuries, multifragmented fractures and subluxations; on the contrary, the less frequent rotational mechanisms are of low energy, almost without axial load, with little soft tissue lesions and may be associated with fractures with a tibia spiral line ${ }^{[3]}$.

In most cases the three components of the tibial pylon or at least two are involved, that is the lateral posterior (Volkmann), the anterolateral (Chaput) and the medial and of course the ligament apparatus, namely, the tibio- fibular ligament posterior inferior, the inferior anterior tibio-fibular and the deltoid, which generates joint displacement (dislocation or subluxation). ${ }^{[4]}$. Between $60 \%{ }^{[5]}$ and $85 \%{ }^{[6]}$ of the cases present fracture of the fibula, associated with the tibial pylon. The fracture line varies, the most frequent being the supra-sindesmal (Weber C) (72\%), while those that occur at the height of the syndesmosis (Weber B) (25\%) and those below the syndesmosis (Weber A) only occur in 3\% of the cases. In fractures with intact fibula the entire load is concentrated in the tibia and increase comminution with its consequences ${ }^{[6}$, 7]. Talus fractures are infrequent and may become disabling, only 3 to $6 \%$ of foot fractures and $0.3 \%$ of the total skeleton occur ${ }^{[8]}$. They are classified according to the anatomical location, that is, of the body with a frequency of 13 to $23 \%$, that of the head $5110 \%$ and that of the neck the most frequent between 50 and $80 \%$. For the latter, the Hawking classification has been used according to displacement, that is to say, Type I not displaced, type II associated with discrete subluxation, type III with moderate sub-astragaline and ankle subluxation and type IV with sub-astragaline subluxation, ankle and scaphoid- talus ${ }^{[9]}$.

A case is presented, of which no previous publication has been found, of an ipsilateral fracture of the right ankle involving the tibial pylon, the talus and the distal fibula, the latter spiral line whose line begins below the syndesmosis.

\section{The case}

It is a 59-year-old female patient who, while running, introduced the fully extended foot into a hole and turned the body to the outside violently with an immediate intense pain in the 
malleolar area; she is urgently transferred to the trauma service of the Los Andes University Hospital (HULA, Merida, Venezuela), where she is indicated a radiological study that shows fracture and dislocation of ankle with the following characteristics: talus-tibial dislocation, fractures of the medial and posterior tibial pylon, with infrasindesmal oblique fracture of fibula (during surgery we found that it was in spiral) and fracture of the neck of the talus with a small fragment (Fig. $1 \mathrm{~A}, \mathrm{~B}$ ). She is intervened following the criteria of the AO / ASIF and a plate is placed on the fibula, two screws in the medial tibial pylon, no implant was placed in the posterior tibial malleolus because it had less than a third of the articular surface ${ }^{[10]}$ and a posterior to anterior screw (Fig. 2 A, B) was placed in talus. There were no local complications of wounds. Three years later, the implants are removed and there is good joint mobility, without pain, but there are radiological signs of degenerative changes (Fig. $3 \mathrm{~A}$, B). The patient walks without pain but decides not to run anymore.

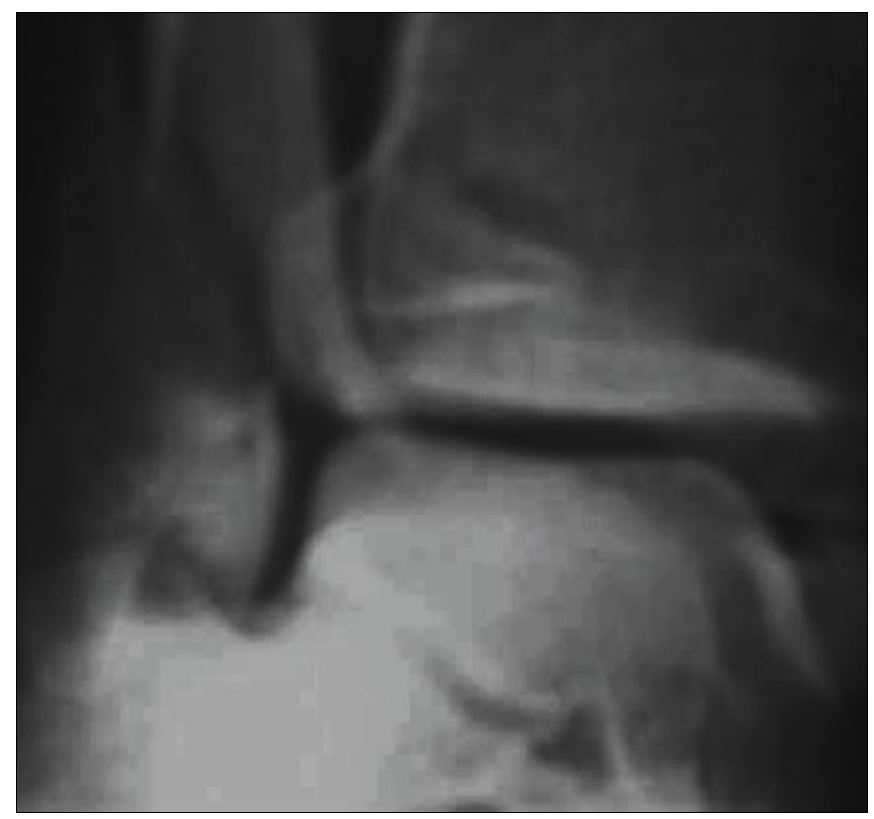

Fig 1A: A fracture of the medial and posterior pylon (arrow) with infrasindesmal oblique fibula (Weber A) is evident.

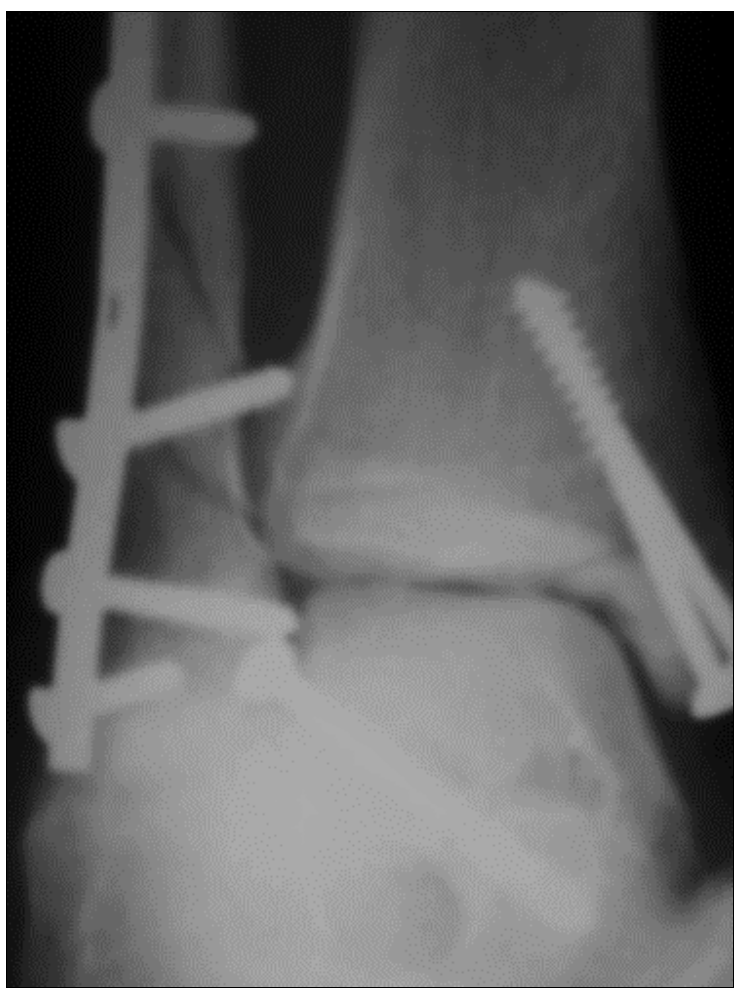

Fig 2A: Immediate post-operative. It is evident that the fracture in the fibula was spiroid.

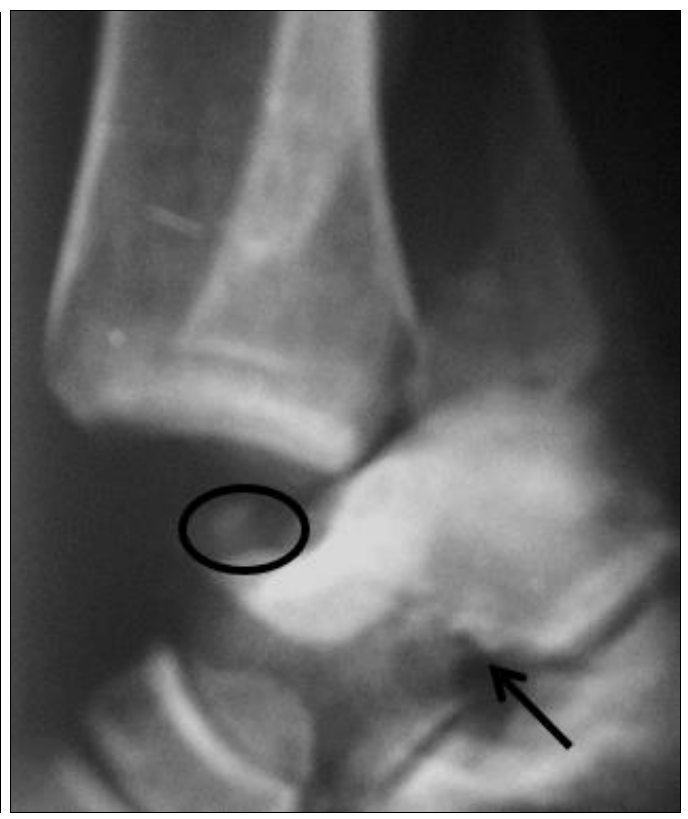

Fig 1B: Profile view shows an evident subluxation, posterior malleolus fracture, fracture of the neck of the talus (arrow) with a fragment for removal of the insertion of the talus- tibial ligament (circle)

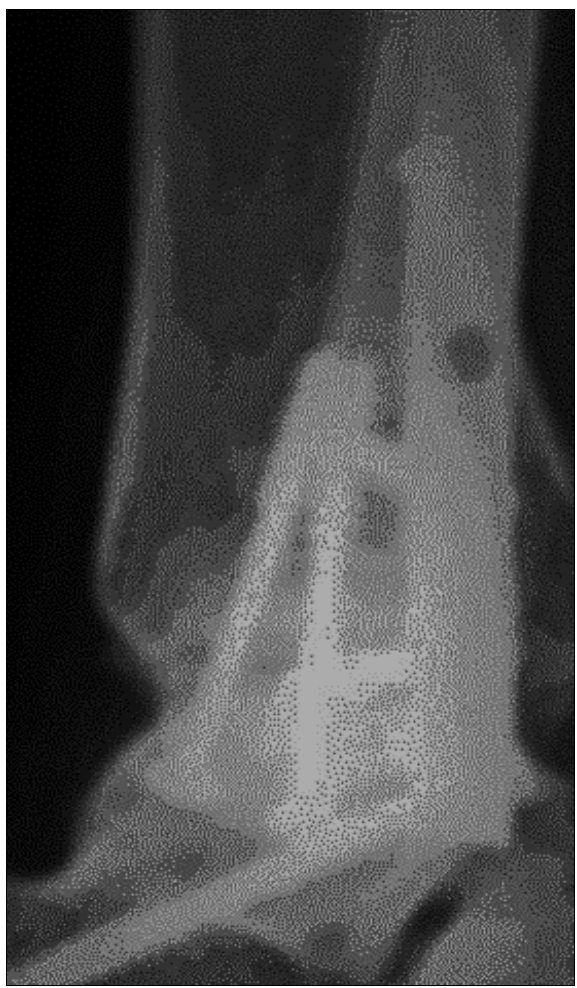

Fig 2B: Profile view with the screw in the talus 


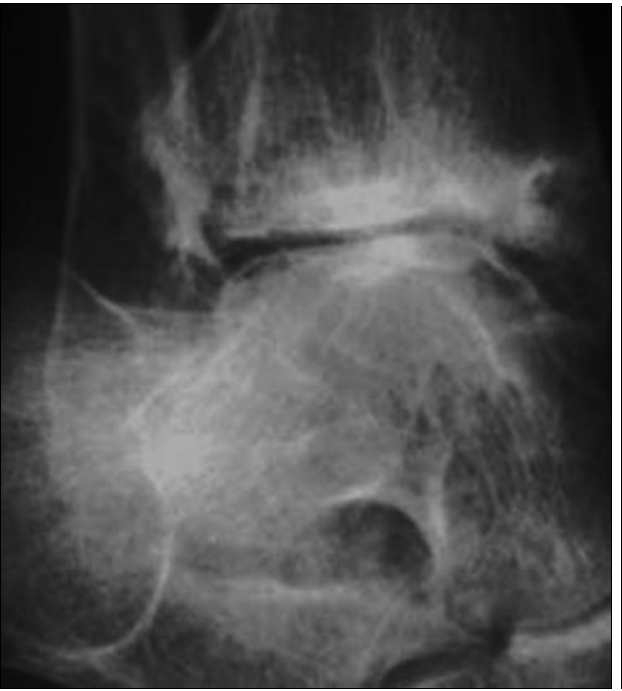

Fig 3A: Three years later without the synthesis material. Medial osteoarthritis signs such as impingement and sclerosis are evident

\section{Discussion}

The case published here is a tibial pylon fracture associated with a non-displaced neck of the talus and fibula. The fracture starts below the syndesmosis and ascends in a spiral line. It is worth pointing out that this line modality has not been reported before.

The pathophysiology of tibial pylon fractures establishes three categories, a high energy one, another by rotation and a last one of low energy in the elderly ${ }^{[11]}$; In our case, the mechanism of injury is due to external rotation, with the foot extended. It first produced a shear fracture of the medial pylon which rotated on its axis, then the posterior malleolus fracture occurred, followed by the fracture of the neck of the talus and ended when completing the fall with the spiral fracture of the fibula and rupture (or disinsertion), at the level of the talus, of the anterolateral talus- tibial ligament. It is important to note that, in order for a fracture of the talus to occur, the sustentaculum talus, as the strongest part of the calcaneus, must act as a fulcrum and in this way the talus rotates between the tibial fibular joint and the calcaneus ${ }^{[12]}$. So far, none of the known classifications shows an injury like our case.

The modality of fracture by rotation has a better prognosis, because there is usually no soft tissue lesion and almost without comminution. That is why for some authors these fractures should no be considered as true pylon tibial ones, but high energy ones ${ }^{[13]}$.

In order to carry out a correct operative planning and in some way the long-term evolution, it is essential to classify the fractures and so far, no classification totally fulfilled its function. Nowadays, the fracture line, the number of fragments, their displacement and comminution can be determined thanks to the CT scan. This is why it is considered an indispensable study for joint fractures, but in our case it was not performed, because our hospital does not have that service $^{[14]}$.

Today, the restoration of the length of the fibula recommended by Ruedi ${ }^{[15]}$ has been called into question ${ }^{[16,}$ ${ }^{17]}$, but in our opinion its beneficial role is undeniable to achieve a better posterior malleolus reduction with syndesmosis and of the entire articular surface. In cases like the one presented, we prefer to reduce the medial area first

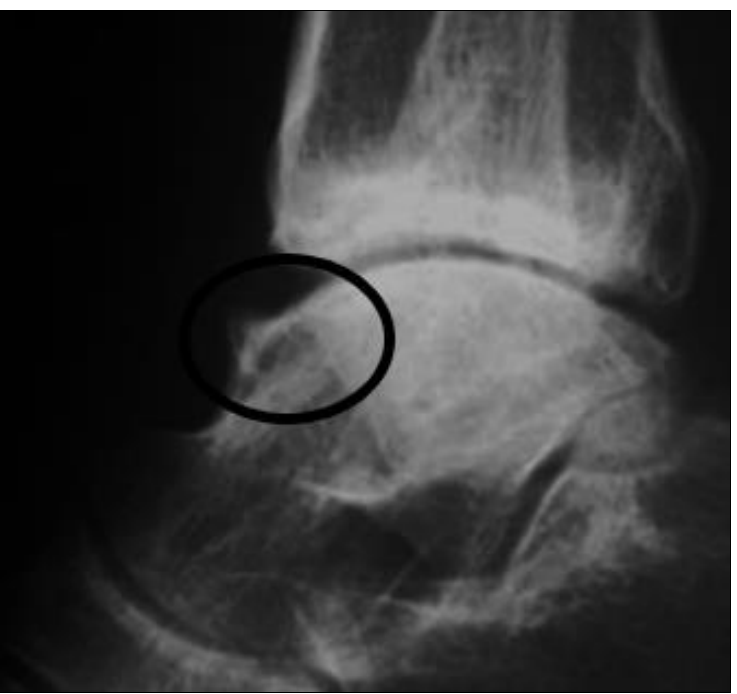

Fig 3B: Three years later. The spicule in the circle, as we see it, is the consolidation of the rupture of the anterior tibial ligament

and then the fibula and we think that a better stability is achieved.

As regards the posterior malleolus, it occurs in $5.6 \%{ }^{[18]}$ of all tibial pylon fractures and every day the role that it plays in it is given more importance. It was originally indicated in the work from Huber et al. in 1996 and Hansen in 2000, notes that tri-malleolar fractures involving the posterior malleolus should be carefully evaluated, because it may be fragmented (a fourth fragment or an osteochondral impaction) resulting from high-energy trauma ${ }^{[19]}$. In fact, they have been divided into: posterior malleolus by rotation and posterior pylon due to high impact vertical trauma. There is even an excellent classification in three types ${ }^{[20]}$. In our case, the posterior malleolus fracture was not accompanied by a lower syndesmal diastasis, a fact reported by some authors ${ }^{[21]}$.

Reduction of the fracture of the talus neck from posterior to anterior is a feasible alternative and sufficient anatomical restoration is achieved ${ }^{[22]}$.

The fracture at issue, despite being caused by rotation, is a tibial pylon one, because there was a significant injury to the articular surface, subluxation of the talus ${ }^{[19,23]}$, along with the talus neck and spiral fracture of the fibula.

In conclusion, tibial pylon fractures are complex lesions, because in some cases the bone lesion goes with the cartilage and soft tissue, especially in those with high impact, and they are a challenge for the team of surgeons. Anyway, we consider that the treatment must be emergency surgery, so as to reduce sequelae, and the posterior approach of the talus seems to us to be an excellent alternative. The author has not found any previous case involving a tibial pylon fracture. Associated with spiral fracture of fibula and talus neck due to rotation with forcing flexion.

\section{Conflicts of interest}

The author do not have any possible conflicts of interest. It is a research involving Human Participants and the informed consent was obtained from she.

\section{Acknowledgement}

A Daniele Thonon for the assistance in grammar. 


\section{References}

1. Mandi DM, Belin RP, Banks J, Barrett B. Pilon fractures. Clin Podiatr Med Surg. 2012; 29:243-278.

2. Tomás-Hernández J. High-energy pilon fractures management: State of the art. EFORT Open Rev. 2017; 1(10):354-361. doi: 10.1302/2058-5241.1.000016.

3. Bear J, Rollick N, Helfet D. Evolution in Management of Tibial Pilon Fractures. Curr Rev Musculoskelet Med. 2018; 11(4):537-545. doi: 10.1007/s12178-018-9519-7.

4. Calori GM, Tagliabue L, Mazza E, de Bellis U, Pierannunzii L, Marelli BM et al. Tibial pilon fractures: which method of treatment? Injury. 2010; 41(11):118390. doi: 10.1016/j.injury.2010.08.041

5. Ruedi TP, Matter P, Allgower M. Intra-articular fractures of the distal tibial end. Helv Chir Acta. 1968; 35:556-582.

6. Liangjun J, Qiang $\mathrm{Z}$, Hang L, Zhijun $\mathrm{P}$ Injury mechanism, fracture characteristics and clinical treatment of pilon fracture with intact fibula-A retrospective study of 23 pilon fractures. J Clin Orthop Trauma. 2017; 8(2):S9-S15. doi: 10.1016/j.jcot.2017.05.002.

7. Weber B, Colton C. Malleolar fractures. In: Müller M, Allgöwer $\mathrm{M}$, Schneider $\mathrm{R}$, Willenegger $\mathrm{H}$, editors. Manual of internal fixation. Vol. Berlin: Springer. 1991; 3:595-612.

8. Bykov Y. Fractures of the talus. Clin Podiatr Med Surg. 2014; 31:509-21. doi: 10.1016/j.cpm.2014.06.004.

9. Radaideh AA, Audat ZA, Saleh AA. Talar Neck Fracture with Dislocation Combined with Bimalleolar Ankle Fracture: A Case Report Am J Case Rep. 2018; 19:320324. DOI: 10.12659/ajcr.907157.

10. De Vries JS, Wijgman AJ, Sierevelt IN, Schaap GR Long-term results of ankle fractures with a posterior malleolar fragment. J Foot Ankle Surg. 2005; 44:211218. doi: 10.1053 .

11. Nieto E. Stress fracture of the medial pylon: A case report in an elderly woman. CPQ Orthopedics. 2019; 3:1.01-04.

12. Peterson L, Romanus B, Dahlberg E. Fracture of the collum tali - An experimental study. J Biomech. 1976; 9:277-9.

13. Bear J, Rollick N, Helfet D. Evolution in Management of Tibial Pilon Fractures. Curr Rev Musculoskelet Med. 2018; 11(4):537-545. doi: 10.1007/s12178-018-9519-7.

14. Leonetti D, Tigani D. Pilon fractures: A new classification system based on CT-scan. Injury. 2017; 48(10):2311-2317. doi: 0.1016/j.injury.2017.07.026. PMID: 28774706.

15. Rüedi TP, Allgöwer M. The operative treatment of intraarticular fractures of the lower end of the tibia. Clin Orthop Relat Res. 1979; (138):105-10.

16. Kurylo JC, Datta N, Iskander KN, Tornetta P. Does the fibula need to be fixed in complex pilon fractures? J Orthop Trauma. 2015; 29(9):424-427. doi: 10.1097/BOT.0000000000000304.

17. Varsalona R, Liu G. Distal tibial metaphyseal fractures: the role of fibular fixation Strat Traum Limb Recon. 2006; 1:42-50.

18. Topliss CJ, Jackson M, Atkins RM Anatomy of pilon fractures of the distal tibia. J Bone Joint Surg Br. 2005; 87(5):692-7

19. Chen DW, Li B, Aubeeluck A, Yang YF, Zhou JQ, Yu GR. Open reduction and internal fixation of posterior pilon fractures with buttress plate. Acta Ortop Bras. 2014; 22(1):48-53.

doi: 10.1590/S1413-78522014000100009.
20. Zhang J, Wang H, Pen C, Qu WC, Duan L, Ren J. Characteristics and proposed classification system of posterior pilon fractures. Medicine (Baltimore). 2019; 98(3):e14133. doi: 10.1097/MD.0000000000014133.

21. Xing W, Wang Y, Sun L, Wang L, Kong Z, Zhang C. Ankle joint dislocation treating dislocated trimalleolar fractures accompanied with the complex posterior malleolus fracture without separation of the tibiofibular syndesmosis. Medicine (Baltimore). 2018; 97(37):e12079. doi: 10.1097/MD.0000000000012079.

22. Sundararajan SR, Badurudeen AA, Ramakanth R, Rajasekaran S. Management of Talar Body Fractures. Indian J Orthop. 2018; 52(3):258-268. doi: 10.4103/ortho.IJOrtho_563_17.

23. Mast JW, Spiegel PG, Pappas JN. Fractures of the tibial pilon. Clin Orthop Relat Res. 1988; (230):68-82. 